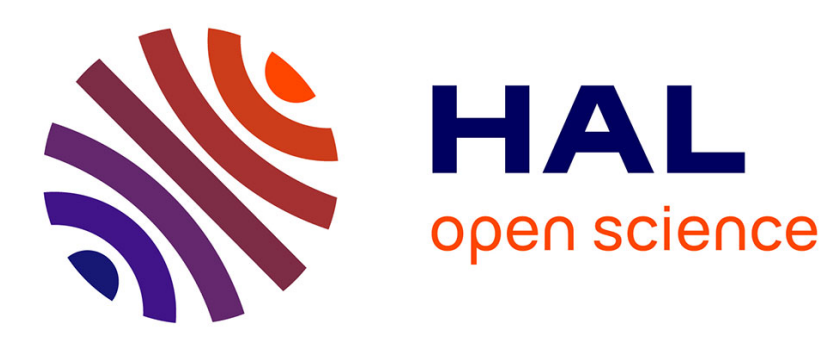

\title{
On the thermal dependence of the twist viscosity in nematic liquid crystals
}

Jacques Prost, G. Sigaud, B. Regaya

\section{To cite this version:}

Jacques Prost, G. Sigaud, B. Regaya. On the thermal dependence of the twist viscosity in nematic liquid crystals. Journal de Physique Lettres, 1976, 37 (12), pp.341-343. 10.1051/jphyslet:019760037012034100 . jpa-00231307

\section{HAL Id: jpa-00231307 https://hal.science/jpa-00231307}

Submitted on 1 Jan 1976

HAL is a multi-disciplinary open access archive for the deposit and dissemination of scientific research documents, whether they are published or not. The documents may come from teaching and research institutions in France or abroad, or from public or private research centers.
L'archive ouverte pluridisciplinaire HAL, est destinée au dépôt et à la diffusion de documents scientifiques de niveau recherche, publiés ou non, émanant des établissements d'enseignement et de recherche français ou étrangers, des laboratoires publics ou privés. 


\title{
ON THE THERMAL DEPENDENCE OF THE TWIST VISCOSITY IN NEMATIC LIQUID CRYSTALS
}

\author{
J. PROST, G. SIGAUD and B. REGAYA
}

Centre de Recherches Paul-Pascal, Domaine Universitaire, 33405 Talence, France

(Reçu le 10 mai 1976, révisé le 22 juillet 1976, accepté le 1er octobre 1976)

\begin{abstract}
Résumé. - Nous montrons que la variation thermique du coefficient de viscosité dynamique de torsion $\gamma_{1}$ du 4-méthoxy-4' n butyl azoxybenzène suit la loi : $\gamma_{1} \sim S \exp (E / k T)$. La généralisation de ce résultat à des nématiques dont le paramètre d'ordre est négatif suggère que l'expression .adéquate pourrait être $: \gamma_{1} \sim|S| \exp (E / k T)$.
\end{abstract}

\begin{abstract}
We show that the twist viscosity $\gamma_{1}$ of 4-methoxy-4' $\mathrm{n}$ butyl azoxybenzene varies according to the law : $\gamma_{1} \sim S \exp (E / k T)$. Generalization to nematics with negative order parameter suggests that the relevant expression could be $: \gamma_{1} \sim|S| \exp (E / k T)$.
\end{abstract}

1. Introduction. - There is a definite interest in finding a proper description of the temperature dependence of the twist viscosity in nematic liquid crystals $[1,2,3]$. This is mainly for two reasons :

First, this kind of viscosity is an original property of nematic liquid crystals not linked to any macroscopic shear and, second, the knowledge of this dependence is essential for subtracting off the background term in the study of the nematic-smectic A phase transition [4].

It has been proposed by Helfrich [1] that if the function describing the temperature behaviour of a nematic is both analytic and universal in the orientational order parameter $S$, the lowest term in the development of $\gamma_{1}$ for small $S$ has to be quadratic : $\gamma_{1} \sim S^{2}$. (The simplest case $\gamma_{1} \sim S$ is ruled out since $S$ can be theoretically positive or negative while $\gamma_{1}$ is constrained to stay positive.) Molecular considerations have led A. F. Martins [3] to propose a form valid over a wide range of $S$ and in agreement with the above mentioned consideration :

$$
\gamma_{1} \sim S^{2} \exp (\xi S / k T)
$$

$\xi$ is given in terms of Maier and Saupe's mean field theory [5]. On the other hand taking as a fundamental variable

$$
Q_{i j}=\frac{3}{2} S\left(n_{i} n_{j}-\frac{1}{3} \delta_{i j}\right)
$$

(which is clearly an assumption since the actual hydrodynamic variable is the director field $\delta n_{i}$ ), Imura and Okano [2] find :

$$
\gamma_{1} \sim \alpha S+\beta S^{2}
$$

Experimentally, the Arrhenius type of dependence is clearly established in the domain where $S$ saturates $[6,7,8]$; however the behaviour in the range where $S$ varies significantly, has been described differently by different authors. We found $\gamma_{1} \sim S \exp (E / k T)$ to be the proper form in the case of MBBA (4-methoxy benzilidene $4^{\prime}-n$ butyl aniline) [6]. Wise et al. [9] found in the case of CBOOA (4-cyanobenzilidene $4^{\prime}$-n octyloxy aniline) that A. F. Martins' theory correctly describes the high temperature behavior of $\gamma_{1}$. However one must note that the temperature range over which these studies have been made is rather narrow and does not allow an easy choice between the two formulae.

2. Experimental results. - We report in this note measurements performed on 4-methoxy $4^{\prime}-n$ butyl azoxy benzene which exhibits a nematic range of more than fifty degrees and an absolute absence of any pretransitional effect on the low temperature side of the nematic domain. Since $\Delta \chi$ (the anisotropic part of the diamagnetic susceptibility tensor, proportional to the order parameter) varies by over a factor of three (Fig. 1) and $\gamma_{1}$ by over more than a factor of thirty (Fig. 2), it should be easy in that case to determine the appropriate fit $\left({ }^{1}\right)$. We have plotted in figure 3 the dependence of $\operatorname{Ln}\left(\gamma_{1} / \Delta \chi^{2}\right)$ as a function of $\left(10^{10} \Delta \chi / T\right)$. If Martins' theory

( $\left.{ }^{1}\right)$ We use the rotating field method to perform the $\gamma_{1}$ measurements $[6,10,11]$ and the Faraday technique for the $\Delta \chi$ measurements $[12,13]$. 
were a universal theory valid for all liquid crystals, figure 3 would exhibit a straight line. Conversely the fact that figure 4 shows such a straight line indicates that $\gamma_{1}$ is proportional to $S \exp (E / k T)$.

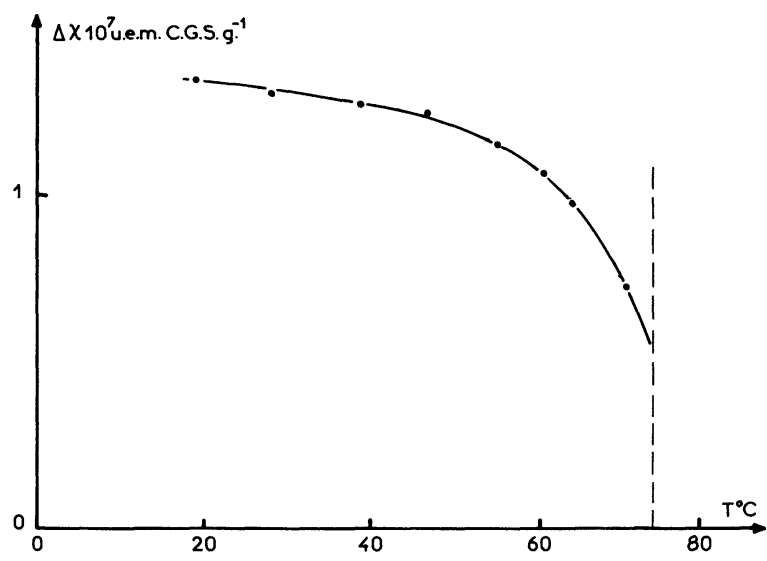

FIG. 1.- Thermal variation of diamagnetic anisotropy $\Delta \chi$ of 4 methoxy $4^{\prime}-n$ butyl azoxybenzene.

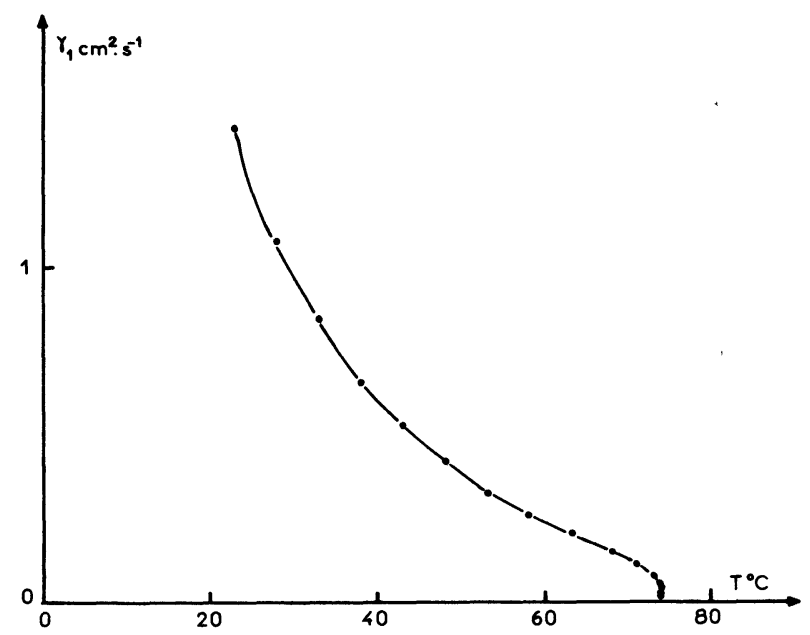

FIG. 2. - Thermal variation of the dynamic twist viscosity coefficient $\gamma_{1}$ of 4 methoxy $4^{\prime}$-n butyl azoxybenzene.

Other thermal dependences such as $\exp (E / k T)$, $S^{2} \exp (E / k T)$ and $S \exp (a S / k T)$ are also clearly ruled out (one would have to assume uncertainties up to $100 \%$ for either the $\gamma_{1}$ or the $S$ measurements to validate such laws). However it has been pointed out to us by A. F. Martins that more complicated forms such as $S^{\gamma} \exp (E / k T)$ could not be totally ruled out. This is correct, but unless extremely accurate measurements, or an adequate theory show the necessity of using these more involved dependences, it seems reasonable to us to consider that $\gamma_{1}$ is essentially proportional to $S \exp (E / k T)$.

In any case, the experiment illustrates two points :

- the activation energy is essentially independent of temperature,

- the functional dependence on $S$ might not be analytic or universal.

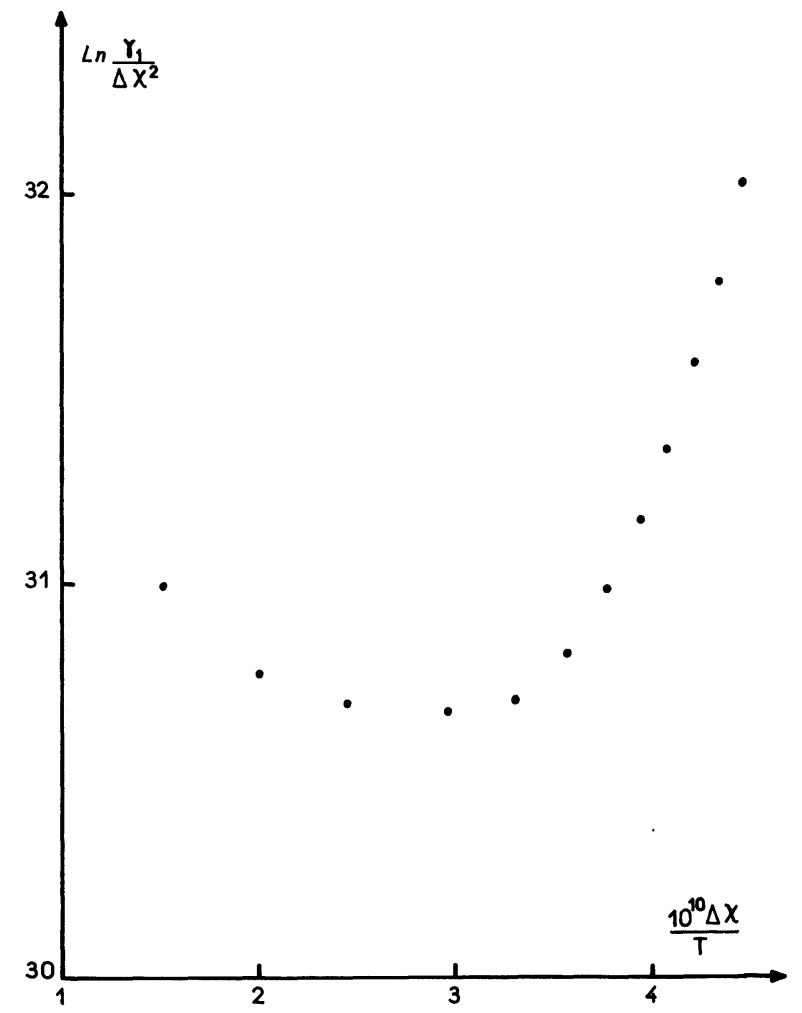

FIG. 3. $-\operatorname{Ln} \gamma_{1} / \Delta \chi^{2}$ versus $10^{10} \Delta \chi / T$.

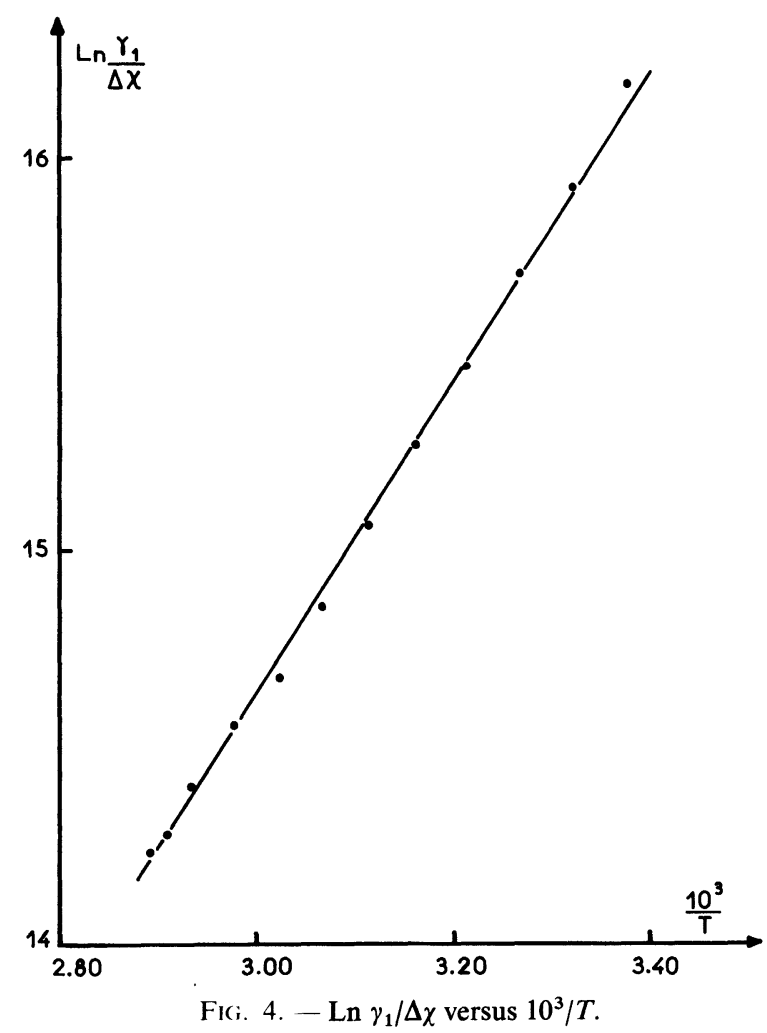

If one were to interpret the $S$ behaviour as arising from an average over microscopic quantities, this would imply that some molecules give a negative contribution to $\gamma_{1}$. This does not contradict the stability requirement since only $\gamma_{1}$ needs to be positive. For example in the case of a nematic with a 
positive $S$, and composed of cigar-shaped molecules, the negative contribution would come from molecules along difficult directions, that is where the long axis lies preferentially perpendicular to the symmetry axis. In the case of a negative $S$ nematic, again composed of cigar shaped molecules, it seems logical to assume that the negative contribution still comes from molecules along difficult directions, which this time turn out to be preferentially parallel to the symmetry axis. The consequence is that the result of the averaging procedure, instead of being proportional to $S$, would rather be proportional to $|S|$.
This is of course, a very simple way of introducing a non-analytic dependence of $\gamma_{1}$ on $S$ and one could certainly imagine more sophisticated alternatives.

As a conclusion we will simply call for more experimental and theoretical work, on the regular temperature behaviour of viscosities in the nematic phase.

Aknowledgments. - It is a pleasure to aknowledge stimulating discussions with M. F. Achard, J. P. Marcerou and H. Gasparoux, and to thank A. F. Martins for valuable comments.

\section{References}

[1] Helfrich, W., J. Chem. Phys. 56 (1972) 3187.

[2] Imura, H. and Okano, K., Japan J. Appl. Phys. 11 (1972) 1440.

[3] Martins, A. F., Port. Phys. 9 (1974) 1.

[4] Brochard, F., J. Physique 34 (1973) 411.

[5] MaIer, W. and SAUPE, A., Z. Naturforsch. A 13 (1958) 564, A 14 (1959) 882, A 15 (1960) 287.

[6] Prost, J., Thesis, Univ. Bordeaux I (1973).

[7] Huang, C. C., Pindak, R. S., Flanders, P. J. and Hoo, J. T., Phys. Rev. Lett. 33 (1974) 400
[8] Langevin, D., J. Physique 36 (1975) 745.

[9] Wise, R. A., Olah, A. and Doane, J. W., J. Physique Colloq. 36 (1975) $\mathrm{Cl}-117$

[10] ZvetKov, H., Acta Physichochim. U.R.S.S. X (1939).

[11] Prost, J. and Gasparoux, H., Phys. Lett. 36A (1971) 245.

[12] Regaya, B. and Gasparoux, H., C. R. Hebd. Séan. Acad. Sci. 232 (1971) 724.

[13] Regaya, B., Thesis, Univ. Bordeaux I (1971).

[14] Martinoty, P. and Candau, S., Mol. Cryst. Liq. Cryst. 14 (1971) 243 